\title{
Adulterated Sexual Enhancement Supplements
}

\section{Citation}

Cohen, Peter, and Bastiaan Venhuis. 2013. JAMA Internal Medicine 173 (13): 1169-1170.

doi:10.1001/jamainternmed.2013.854

\section{Permanent link}

http://nrs.harvard.edu/urn-3:HUL.InstRepos:40506765

\section{Terms of Use}

This article was downloaded from Harvard University's DASH repository, and is made available under the terms and conditions applicable to Open Access Policy Articles, as set forth at http:// nrs.harvard.edu/urn-3:HUL.InstRepos:dash.current.terms-of-use\#OAP

\section{Share Your Story}

The Harvard community has made this article openly available.

Please share how this access benefits you. Submit a story.

Accessibility 
Title: More than mojo: adulterated sexual enhancement supplements

\section{Authors:}

Pieter Cohen, MD (corresponding author)

Harvard Medical School and Cambridge Health Alliance

1493 Cambridge Street, Cambridge, MA, 02139

Tel: 617-665-1016

Pager: 617-546-9379

Fax: 617-665-1671

Email: pcohen@challiance.org

Dr. B.J. (Bastiaan) Venhuis, PhD

National Institute for Public Health and the Environment

Dept. Pharmaceuticals and Medical Devices

Anthonie van Leeuwenhoeklaan 9 | 3721 MA | Bilthoven

The Netherlands

Word count: 1,197

Funding: None

Conflict of interests: None

Acknowledgement: Rachael Bedard, MD, Harvard Medical School, for thoughtful comments on earlier versions of the manuscript.

No compensation was received by Dr. Bedard for her assistance. 
Over the last five years the US Food and Drug Administration (FDA) has identified more than 330 dietary supplements adulterated with active pharmaceuticals.(1) While the FDA has recalled some of these products, recent research suggests that, even after the recalls, products may remain available over the Internet and on store shelves.(2) One of the largest categories of tainted supplements are those sold to enhance sexual performance. A combination of manufacturer scrupulousness and consumer demand has created a huge market for dangerous sexual enhancement supplements. One recent example, Rock Hard for Men, sold as a "natural" supplement actually contains two potent prescription drugs - a phosphodiesterase-5 (PDE-5) inhibitor, tadalafil, and a sulfonylurea, glyburide.(3) This combination of medications is of particular concern because a very similar combination discovered in other sex supplements has already led to over a dozen deaths.(4) If physicians, legislators and regulators do not act decisively soon, more deaths may follow.

The quantity of adulterated sex supplements sold in the US is staggering. One Utah manufacturer produced over one million capsules a month of pharmaceutically tainted sexual enhancement supplements which netted the company over \$2 million in 3 years.(5) Some men may choose these products to avoid the inconvenience, embarrassment and cost of a doctor's visit. Other consumers may have contraindications to prescription PDE-5 inhibitors, such as sildenafil (Viagra) or tadalafil (Cialis), and turn to natural products because they perceive them to be safer alternatives to treating sexual troubles. In the United States (US), these sexual enhancement products are sold as dietary supplements and are legally permitted to make claims such as "enhances sexual performance" without evidence of efficacy or safety.(6) To garner repeat customers, many manufactures clandestinely add prescription medications to their products. But the US sales represent only a small fraction of the global market for adulterated pills - one study in Singapore found that $77 \%$ of "natural" sex supplements collected from informal markets contained undeclared pharmaceuticals.(7) Even more concerning, more than half of the adulterated products contained greater than therapeutic dosages of the pharmaceutical adulterants.(7)

Unintended consumption of PDE-5 inhibitors may have important health consequences. When pharmaceutical quality sildenafil or tadalafil is prescribed under medical supervision, men can be warned that they might experience visual changes and modest decreases in blood pressure, and are advised to avoid co-administration of nitrates which can lead to life-threatening drops in blood pressure. However, when supplements are adulterated with PDE-5 inhibitors, dosages vary widely, side effects are unanticipated and drug-drug interactions cannot be avoided. The risks of adulterated sex supplements are increased further when PDE-5 inhibitors are combined with other pharmaceuticals such as glyburide.(4) In the Singapore study, $18 \%$ of sexual enhancement supplements contained two or more pharmaceutical ingredients including lidocaine, naproxen and chloramphenicol.(7)

Combinations of well-characterized prescription drugs can be detected by astute clinicians and regulators using routine toxicological tests. Recently, however, manufacturers of sex supplements have increasingly turned to entirely novel pharmaceutical products that are not easily identified and have no regulatory status. Some new ingredients appear to be based on drugs that were patented but failed the development process. In 2004 the FDA identified a PDE-5 inhibitor with subtle changes to its chemical structure - one of sildenafil's methyl groups had been replaced with an ethyl group. Although these modified PDE-5 inhibitors are often benignly termed analogues, no human safety data exists for these novel compounds.

Alarmingly, the diversity of PDE inhibitor analogues has increased dramatically from less than a half-dozen in the early 2000 s to over 45 different analogues today.(8) PDE-5 inhibitor analogues have appeared in pills, powders and even instant coffee.(1) A recent analysis of seized adulterated sex supplements in the Netherlands revealed that nearly $75 \%$ contained these experimental drugs.(8) The FDA recently warned that a single product, Mojo Nights, contained not only sildenafil and tadalafil but also three analogues.(9)

The health risks posed by analogues of PDE- 5 inhibitors to the unwitting consumer are profound. In recent years, more exotic structures with less PDE-5 selectivity have been identified.(10) Eleven different families of phosphodiesterases are involved in a wide range of metabolic processes. Drugs such as sildenafil and tadalafil have passed the rigorous drug development process and are designed to inhibit only one family of phosphodiesterases, PDE-5, and selectively target the corpus cavernosum. Less-selective inhibitors may affect many other organ systems. Analogues have been identified that nonselectively inhibit both PDE-5 and PDE-6, potentially increasing the risk of retinal injury.(Figure) Other analogues inhibit the PDE-1 family of 
receptors found in the brain, heart, kidney and liver. As these drugs have never been studied in humans, their adverse effects are completely unknown.

Common adverse effects of PDE-5 inhibitors such as flushing, lightheadedness or dyspepsia can be identical to those of niacin and yohimbe, ingredients often listed on sexual enhancement supplement labels. Therefore, clinicians might not suspect adulterants nor report reactions to the FDA when yohimbe or niacin are listed on the label. Similarly, the FDA and other regulators face serious obstacles in identifying these products in a timely fashion. The current laws regulating supplements assume that all supplements are safe until the FDA proves otherwise. When the FDA is faced with entirely novel chemical compounds, the identification of the new ingredient is a complex and time-consuming task - the inevitable delays before the FDA acts lead to prolonged exposure of US consumers to these tainted supplements.

We believe there are several concrete steps that can be taken to decrease the risk to consumers. Clinicians should advise patients that there are only two types of products available: 1) those that might be safe but don't work, and 2) those that might work but aren't safe. Therefore, patients should be counselled to avoid all of them. To further decrease use of sex supplements, we recommend having a low threshold for prescribing PDE-5 inhibitors when requested, so that physicians can ensure patients receive high-quality products and are counselled appropriately before their use. Patients who are keen on trying a sexual enhancer found in nature may wish to try the active ingredient in yohimbe, yohimbine, which is available only by prescription in the US (appropriate counselling regarding adverse effects is still important). Clinicians caring for patients who experience unexplained symptoms or significantly improved erections after using sex supplements should consider the possible role of adulterants, obtain samples, and report cases to the FDA via MedWatch.

Legislators should revise the law regulating dietary supplements such that manufacturers are not permitted to claim that a product will improve one's sexual function (or any other function) until data is provided to the FDA to support such a claim. In addition, using the model of the US Drug Enforcement Agency's analogue provision that permits analogues of Schedule I and Schedule II substances to be considered scheduled substances, all PDE-5 inhibitor analogues should, a priori, be legally considered unapproved new drugs. This designation would decrease administrative and legal barriers that currently delay the FDA's response to each new analogue. Regulators worldwide should collaborate to create a global database of identified analogues with their mass spectrometry characteristics to permit swift identification of illegal products. Implementing these recommendations now will increase the risk and decrease the profit for those supplement manufacturers who continue to expose consumers to dangerous tainted supplements.

\section{References:}

1. US Food and Drug Administration. Tainted supplements CDER. http://www.accessdata.fda.gov/scripts/sda/sdNavigation.cfm?filter=\&sortColumn=1d\&sd=tainted supplements_cder\&page=1. Accessed Dec 6, 2012.

2. Cohen PA, Benner C, McCormick D. Use of a pharmaceutically adulterated dietary supplement, Pai You Guo, among Brazilian-born women in the United States. J Gen Intern Med 2012;27(1):5156.

3. Therapeutic Goods Administration, Australian Government. Safety advisory: Rock Hard for Men tablets. 29 Aug 2012. http://www.tga.gov.au/safety/alerts-medicine-rock-hard-120829.htm. Accessed Dec 6, 2012.

4. Poon WT, Lam YH, Lee HH, et al. Outbreak of hypoglycaemia: sexual enhancement products containing oral hypoglycaemic agent. Hong Kong Med J 2009;15:196-200.

5. Canham M. Feds plow new ground in spiked supplement case. Salt Lake City Tribune Oct 1, 2011.

6. Cohen PA. Assessing supplement safety - the FDA's controversial proposal. N Eng J Med 2012; 366(5): 389-391.

7. Low MY, Zeng Y, Li L, et al. Safety and quality assessment of 175 illegal sexual enhancement products seized in red-light districts in Singaport. Drug Saf 2009;32(12):1141-1146. 
8. Venhuis BJ, de Kaste D.Towards a decade of detecting new analogues of sildenafil, tadalafil and vardenafil in food supplements: A history, analytical aspects and health risks." J Pharm Biom A 2012;69:196-208.

9. Food and Drug Administration. Public notification: "Mojo Nights" contains hidden drug ingredients. May 25, 2012.

http://www.fda.gov/Drugs/ResourcesForYou/Consumers/BuyingUsingMedicineSafely/MedicationHea IthFraud/ucm305594.htm Accessed Dec 6, 2012.

10. Balayssac S, Gilard V, Zedde C, Martino R, Malet-Martino M. Analysis of herbal dietary supplements for sexual performance enhancement: First characterization of propoxyphenylthiohydroxyhomosildenafil and identification of sildenafil, thiosildenafil, phentolamine and tetrahydropalmatine as adulterants. J Pharm Biom A 2012;63:135-150. 